УДК 336.761

Н. В. Кузнецова

Байкальский государственный университет, г. Иркутск, Российская Федерация

Л. В. Казанцев

Байкальский государственный университет,

г. Иркутск, Российкая Федерация

\title{
ФУНДАМЕНТАЛЬНЫЙ И ТЕХНИЧЕСКИЙ АНАЛИЗ ФОНДОВОГО РЫНКА
}

\begin{abstract}
АНнотАция. Фондовый рынок - неотъемлемая часть экономики любой страны. Оказывая существенное влияние на развитие различных сфер бизнеса, путем аккумуляции временно свободных денежных средств и их перераспределения, рынок обеспечивает притоки собственных и зарубежных инвестиций в реальный сектор экономики. Все операции на фондовых рынках так или иначе связаны с риском, поэтому в каждой конкретной ситуации необходимо учитывать разные его виды и принимать правильные решения. Исследование фондового рынка и оценка всевозможных рисков возможны посредством двух видов анализа - фундаментального и технического. Оба подхода имеют своих противников и почитателей. В статье рассмотрен подход совместного применения фундаментального и технического анализа: плюсы и минусы, проблемы и преимущества. Описываются механизмы функционирования и развития фондового рынка, являющиеся одним из актуальнейших вопросов не только российской экономики, но и мировой экономики в целом.

кЛЮЧЕВЫЕ СЛОВА. Фондовый рынок; фундаментальный анализ; технический анализ. ИНФОРМАЦИЯ О СТАТЬЕ. Дата поступления 7 августа 2016 г.; дата принятия к печати 27 августа 2016 г.; дата онлайн-размещения 26 сентября 2016 г.
\end{abstract}

N. V. Kuznetsova Baikal State University, Irkutsk, Russian Federation

L. V. Kazantsev Baikal State University, Irkutsk, Russian Federation

\section{FUNDAMENTAL AND TECHNICAL ANALYSIS OF STOCK MARKET}

\begin{abstract}
The stock market is an integral part of economy in any country. Through exerting a significant impact on developing various business spheres, by accumulating temporarily free monetary funds and their redistribution, the market provides inflows of own and foreign investments into real sectors of economy. All operations in the stock market are somehow connected with risks, that's why in any specific situation it is necessary to consider its various types and to make proper decisions. Investigation of the stock market and assessment of various risks can be made possible through two types of analysis: fundamental and technical ones. The both approaches have their opponents and followers. The article considers an approach of combined use of fundamental and technical analyses: pluses and minuses, problems and advantages. It describes the mechanisms of functioning and development of the stock market that are the most topical issues of not only Russian economy but also of the world economy on the whole.

KEYWORDS. Stock market; fundamental analysis; technical analysis.
\end{abstract}

ARTICLE INFO. Received August 7, 2016; accepted August 23, 2016; available online September 26, 2016.

Фондовый рынок, как классическая форма организации торговли финансовыми инструментами, является неотъемлемой частью экономики любой страны, поэтому изучение механизмов его функционирования и развития - один из ак-

(C) Н. В. Кузнецова, Л. В. Казанцев, 2016

\section{Baikal Research Journal}


туальнейших вопросов всей экономики в целом. Подтверждением этому являются достижения лауреатов Нобелевской премии по экономике 2013 г. Ю. Фамы, Р. Шиллера и Л.-П. Хансена в анализе эффективности финансовых рынков. Научные разработки указанных авторов заключаются в создании ключевых моделей ценообразования на финансовом рынке, методов тестирования этих моделей, а также концепции поведенческих финансов как одного из объяснений неэффективности и иррациональности фондового рынка [1, с. 4].

По мнению Н. А. Звягинцевой, современный этап развития отечественной экономики неразрывно связан с проблемой активизации инвестиционной деятельности для обеспечения устойчивого экономического роста и повышения качества жизни населения [2, с. 5]. Опыт развитых стран мира показывает, что реализовывать комплексный подход в развитии инвестиционных процессов позволяют следующие моменты:

- широкое применение рыночных механизмов стимулирования инвестиционной деятельности с использованием механизмов рынка ценных бумаг;

- гибкое регулирование государственных и частных инвестиций для решения задач экономического роста;

- формирование программ привлечения внутренних и внешних инвестиций через рынок ценных бумаг;

- создание системы инвестиционных фондов различного типа.

Рассматривая и оценивая российский фондовый рынок, можно отметить следующее:

- незрелость рынка;

- низкий уровень капитализации отечественных компаний ( 10\% от номинальной стоимости валового внутреннего продукта, тогда как в развитых странах этот показатель колеблется в пределах от 55 до 60 \%);

- использование акционирования, как формы передела собственности;

- низкая ликвидность большинства российских ценных бумаг;

- повышение информационной прозрачности компаний в динамике;

- развитие рынка ориентировано на развитие региональных рынков и выведение на эти рынки значительного числа акционерных обществ в интересах привлечения инвестиций;

- значительный вес спекулятивных операций благодаря широкому использованию современных компьютерных систем;

- тенденции развития рынка аналогичны тенденциям, преобладающим сегодня на мировом рынке: глобализация, коммерциализация и универсализация.

Помимо перечисленных особенностей российский фондовый рынок очень чувствителен к любым макроэкономическим событиям. Одним из ярких примеров является ситуация, произошедшая в 2014 г. Сначала обострение геополитической обстановки, связанное с событиями «крымской весны» и жестких санкций Запада на Россию, привело к уходу иностранных инвесторов с российского фондового рынка. При относительно малой ликвидности большинства ценных бумаг российских эмитентов это привело к снижению их котировок. Следующим ударом по рынку стало резкое падением мировых цен на нефть с 115 до 60 дол. за баррель [3]. Отмена Центральным банком РФ «валютного коридора» привела к росту курса американского доллара выше 70 р. Возникшая всеобщая паника населения, связанная с падением национальной валюты, грядущие подорожание импортных товаров и покупка их «впрок», привели к массовому изъятию рублевых вкладов (а их большая часть $73,9 \%$ ), вызвав тем самым снижение денежной ликвидности в банках. Поднятие ключевой ставки Центральным банком РФ до 17 \% также резко подняло стоимость заемных денег как у банков, так и у брокеров, предоставляющих доступ на фондовые рынки. Брокерам же пришлось повышать величину обеспечения по маржи-

\section{Baikal Research Journal}


нальным сделкам, что привело к принудительным закрытиям риск-менеджерами позиций клиентов (margincall), повлекшее за собой еще больший обвал котировок по многим эмитентам.

Приведенный пример ярко иллюстрирует, что все операции на фондовых рынках так или иначе связаны с риском, поэтому в каждой конкретной ситуации необходимо учитывать разные его виды и принимать правильные решения. Выделяют два основных вида рисков: кредитный и рыночный. Под кредитным риском понимают риск невыплаты процентов по ценной бумаге. Рыночный риск, который называется процентным, связан с колебаниями рыночной цены той или иной ценной бумаги в связи с изменением ставки процента на финансовом рынке.

Кредитный риск характеризует кредитоспособность и надежность эмитента ценной бумаги. Операция оценки качества ценной бумаги в отношении кредитного риска называется рейтингом. Присвоением рейтинга занимаются неправительственные, коммерческие компании. В рамках процедуры присвоения кредитного рейтинга агентством выполняется детальный анализ качественных и количественных показателей деятельности.

Рейтинги ценных бумаг служат ориентиром для инвесторов, они периодически пересматриваются и при ухудшении общего финансового положения эмитента могут быть понижены. Присвоение рейтинга происходит в результате большой аналитической работы по анализу финансового состояния эмитента. В ходе анализа, как правило, определяются ключевые коэффициенты, по которым и судят о качестве бумаг эмитента. Опираться только на рейтинги ценных бумаг не всегда целесообразно, поэтому анализ инвестиционной привлекательности как всего рынка ценных бумаг, так и отдельных акций становится важнейшей задачей инвестора, от решения которой зависит его выбор.

В распоряжении инвестора есть два инструмента анализа и прогнозирования рынка ценных бумаг: технический и фундаментальный анализ.

Разделение финансовых аналитиков на две большие группы основано на используемом ими методе анализа. Одни из них применяют фундаментальный анализ их называют фундаментальными аналитиками, другие используют технический анализ - их называют техническими аналитиками. Если фундаментальные аналитики исследуют закономерности, которые будут действовать в будущем, то взгляд технических аналитиков обращен в прошлое [4, с. 807].

Возникновение технического анализа произошло в начале 20 -х гг. прошлого века. В то время информацию о деятельности компаний найти было почти невозможно. Обособление экономического анализа в специальную отрасль знаний только начинало осуществляться. В дальнейшем, с развитием экономического анализа, с ростом законодательной базы и усилением нормативного регулирования, компании обязали раскрывать данные о своей производственной и финансовой деятельности, и у инвесторов появилась возможность ознакомиться с текущим имущественным и финансовым состоянием компании. Это способствовало зарождению фундаментального анализа.

Впервые понятие «фундаментальный анализ» было дано в книге Б. Грэма и Д. Додда «Анализ ценных бумаг», вышедшей в свет в 1934 г. в США. Фундаментальный анализ был определен как инструмент для предсказания будущих биржевых цен на акции [5, с. 414]. В более поздних научных изданиях фундаментальный анализ представлен как процесс «исследования состояния экономики, отрасли и финансового положения компании с целью определения рыночной стоимости акций компании» .

Таким образом, фундаментальный анализ - это оценка множества внешних и внутренних факторов, существенно влияющих на финансовую и хозяйственную деятельность компании, результаты которой находят отражение в рыночной стоимости ее ценных бумаг. Таких факторов великое множество. Это и деятельность конкурен-

\section{Baikal Research Journal}

электронный научный журнал Байкальского государственного университета 
тов, и политическая ситуация в стране, и эффективность менеджмента, и неукоснительное соблюдение прав акционеров общества, и финансовое положение компании.

Различают четыре этапа фундаментального анализа:

1. Анализ общего состояния экономики.

2. Отраслевой анализ.

3. Анализ финансового состояния компаний-эмитентов.

4. Определение справедливой стоимости акций компаний.

На первом этапе фундаментального анализа осуществляется анализ общего состояния экономики на основе экономических показателей страны и анализа мировых фондовых индексов.

К экономическим показателям страны, на которые наиболее заметно реагирует отечественный рынок акций, относятся:

- валовой внутренний продукт;

- денежная масса;

- золотовалютные резервы;

- торговый баланс;

- ставка рефинансирования.

Данные показатели рассчитываются по единым методикам для всех развитых стран и публикуются на сайте Министерства экономического развития и торговли РФ. Поскольку экономика России интегрирована в мировую, опытные инвесторы начинают свой день с анализа (табл. 1) следующих мировых фондовых индексов:

- американский промышленный индекс Доу-Джонса;

- S\&P-500 - индекс, рассчитываемый американским аналитическим агентством Standard \& Poor's;

- Nikkei 225 - один из важнейших фондовых индексов Японии;

- MSCI Emerging Markets (EM, MSCI Emerging Markets) - индекс биржевых рынков стран с развивающейся экономикой, включенный в семейство индексов Morgan Stanley Capital Int. В него включены акции крупнейших компаний с большой и средней капитализацией из 27 развивающихся стран (Россия, Мексика, Аргентина, Таиланд и т. д.), рассчитывается компанией Morgan Stanley;

- немецкий DAX (Deutscher Aktienindex) — важнейший фондовый индекс Германии;

- французский САС-40 (КЭК-40) - важнейший фондовый индекс Франции;

- английский FTSE (Футси 100) - ведущий индекс Британской фондовой биржи, который рассчитывается независимой компанией FTSE Group и им совместно владеют агентство Financial Times и Лондонская фондовая биржа [6, с. 15].

Второй этап фундаментального анализа, именуемый отраслевым анализом, призван определить перспективы той или иной компании в зависимости от ее отраслевой принадлежности. Известно, что в разные периоды времени перспективы той или иной отрасли бывают различны.

Таблица 1

Паралетры фондовых индексов

\begin{tabular}{|l|l|l|l|}
\hline \multicolumn{1}{|c|}{ Индекс } & \multicolumn{1}{|c|}{ Состав } & \multicolumn{1}{|c|}{ Способ взвешивания } & \multicolumn{1}{|c|}{ Метод расчета } \\
\hline DJIA & 30 голубых фишек NYSE & По цене & Арифметический \\
\hline S\&P-500 & Выборка акций TSE & По рыночной стоимости & Арифметический \\
\hline Nikkei 225 & 225 акций & По цене & Арифметический \\
\hline MSCI & 20 промышленных голубых фишек & По цене & Арифметический \\
\hline DAX & Выборка из 30 голубых фишек & По рыночной стоимости & Арифметический \\
\hline CAC-40 & 40 акций & По рыночной стоимости & Арифметический \\
\hline FTSE & 100 акций & По рыночной стоимости & Арифметический \\
\hline
\end{tabular}

Составлено по: [7, с. 65].

\section{Baikal Research Journal}


Третий этап фундаментального анализа является наиболее трудоемким. Он представляет собой анализ финансового состояния компаний-эмитентов. В первую очередь изучается годовая бухгалтерская отчетность: баланс, отчет о финансовых результатах, отчет о движении денежных средств. Целью изучения годовой бухгалтерской отчетности является определение структуры активов и источников формирования активов компании, рентабельности бизнеса, ликвидности, платежеспособности и финансовой устойчивости компании, ее деловой активности и кредитоспособности. Кроме финансового анализа также необходим анализ состояния и перспективы развития менеджмента, организационных и коммерческих условий работы.

На четвертом этапе анализа определяется рыночная стоимость акций компаний или компаний в целом. При этом используется сравнительный анализ. Главное достоинство сравнительного анализа - возможность получения мгновенной оценки рассматриваемого актива. Сравнительный анализ также называют рыночным, мультипликаторным, так как он подразумевает расчет следующих мультипликаторов:

- отношение рыночной капитализации к чистой прибыли $P$ / $E$;

- отношение рыночной капитализации к выручке $P$ / $S$.

Мультипликатор $P$ / $E$ очень широко используется аналитиками, так как нет необходимости в построении прогнозов будущих выгод и рисков их получения; требует минимальных затрат времени на поиск информации и проведение расчетов; именно прибыль традиционно считается главным стимулом инвестирования $[8$, c. 551,554$]$.

Если компания убыточна и применить мультипликатор $P$ / $E$ невозможно, можно использовать мультипликатор $P$ / $S$, т. е. рассчитать отношение рыночной капитализации к выручке. Мультипликаторы позволяют понять, насколько инвесторы на рынке больше ценят $1 \mathrm{p}$. выручки или прибыли компании $A$ по сравнению с $1 \mathrm{p}$. выручки или прибыли компании $Б$ [8, с. 562].

Возникновение технического анализа произошло раньше фундаментального, который базируется на данных бухгалтерской отчетности организации-эмитента. В отсутствии отчетных данных или в ситуации, когда инвесторам была недоступна информация об организации-эмитенте, единственным объектом анализа был сам рынок. Изучение динамики показателей самого рынка и лежит в основе технического анализа. Построение различных графиков, изучение изменений рыночной цены в динамике позволяет инвестору принять верное решение.

Традиционный технический анализ состоит в построении диаграмм, изучении только что заключенных контрактов и т. д. В первую очередь, он направлен на изучение динамики цен на конкретный финансовый инструмент с целью предугадывания движения цены в ближайший период времени. Для этого аналитики отыскивают на графиках поведения цен повторяющиеся характерные очертания, фигуры и выдают рекомендации в предположении дальнейшего движения цены по этой фигуре.

Фигуры технического анализа строятся на основе реальных сделок. В результате они показывают, как инвесторы и спекулянты распорядились своими средствами. Сталкиваясь с одними и теми же ситуациями, инвесторы и спекулянты в силу психологических факторов снова и снова реагируют одинаково, поэтому фигуры технического анализа можно использовать для оценки вероятности такого же развития событий в будущем при такой же рыночной ситуации [9, с. 28].

Технический анализ фондовых рынков зачастую рассматривается в отрыве от фундаментального. Однако эти методы взаимосвязаны и дополняют друг друга. Если фундаментальный анализ сосредоточен на движении рынка в целом под влиянием внешних факторов, то технический связан с изучением динамики цен, отражает потребности покупателей и продавцов, спрос и предложение, определяющие курс ценной бумаги. Технический анализ также называют графическим, поскольку

\section{Baikal Research Journal}

электронный научный журнал Байкальского государственного университета 
графическое представление анализируемой информации - основной метод технического анализа фондового рынка [10, с. 111].

Технический анализ, в отличие от фундаментального, может прогнозировать поведение акций на краткосрочный период (на день или неделю), но не может предсказать, что произойдет с акциями компании в будущем, в перспективе на долгосрочный период. Как правило, на технический анализ поэтому опираются фондовые спекулянты, а фундаментальный используют инвесторы, ориентирующиеся на долгосрочное вложение средств.

По мнению И. С. Межова, фундаменталисты считают, что любая ценная бумага имеет внутренне присущую ей ценность, которая может быть количественно оценена как дисконтированная стоимость будущих поступлений. Технократы же утверждают, что для определения текущей стоимости конкретной ценной бумаги достаточно знать лишь динамику ее цены в прошлом [11, с. 94].

Совместное использование фундаментального и технического анализа имеет свои достоинства и недостатки. Наиболее часто целью совмещения методов анализа является то, чтобы с помощью фундаментального анализа определять наиболее интересный для инвестирования актив, а технический анализ уже применяется для подбора подходящей точки входа в рынок. В таком совмещении методов фундаментальный анализ дает экономическую основу для сделки, а технический анализ, рассматривая психологию участников рынка, обеспечивает более подходящие даты входа в сделку и выхода из нее.

Исследуя положительные и отрицательные стороны фундаментального и технического анализов (табл. 2), можно сделать вывод о преобладании плюсов у технического анализа. Это и незначительный объем информации для исследования, необязательное знание специфики отрасли, независимость методологии анализа от временного масштаба, незначительный период времени для проведения анализа, многообразие инструментов анализа. Минусов всего два - краткосрочность предоставляемого анализом прогноза и знание большого количества фигур анализа и обладание особенным мышлением.

Таблица 2

Положительные и отрицательные стороны фундалентального и технического анализов

\begin{tabular}{|c|c|c|c|c|}
\hline \multirow[t]{2}{*}{ Признак } & \multicolumn{2}{|c|}{ Фундаментальный анализ } & \multicolumn{2}{|c|}{ Технический анализ } \\
\hline & Основание & $\begin{array}{l}\text { Характе- } \\
\text { ристика }\end{array}$ & Основание & $\begin{array}{l}\text { Характе- } \\
\text { ристика }\end{array}$ \\
\hline $\begin{array}{l}\text { Информация для } \\
\text { анализа }\end{array}$ & $\begin{array}{l}\text { Требуется значительный } \\
\text { объем информации }\end{array}$ & - & $\begin{array}{l}\text { Требуется незначитель- } \\
\text { ный объем информации }\end{array}$ & + \\
\hline $\begin{array}{l}\text { Знание специфики } \\
\text { отрасли }\end{array}$ & Требуется & - & Не требуется & + \\
\hline $\begin{array}{l}\text { Зависимость мето- } \\
\text { дологии анализа от } \\
\text { временного масштаба }\end{array}$ & $\begin{array}{l}\text { Исследования осущест- } \\
\text { вляются в динамике за } \\
\text { ряд лет }\end{array}$ & - & $\begin{array}{l}\text { Исследования могут } \\
\text { осуществляться на пя- } \\
\text { тиминутных графиках }\end{array}$ & + \\
\hline $\begin{array}{l}\text { Период времени для } \\
\text { проведения анализа }\end{array}$ & Значительный & - & Незначительный & + \\
\hline $\begin{array}{l}\text { Многообразие ин- } \\
\text { струментов анализа }\end{array}$ & Да & + & Да & + \\
\hline $\begin{array}{l}\text { Сложность изучения } \\
\text { и применения ин- } \\
\text { струментов анализа }\end{array}$ & $\begin{array}{l}\text { Требуются знания бух- } \\
\text { галтерской отчетности, } \\
\text { методик расчета финан- } \\
\text { совых коэффициентов и } \\
\text { их трендового анализа }\end{array}$ & - & $\begin{array}{l}\text { Требуются знания боль- } \\
\text { шого количества фигур } \\
\text { анализа и обладание } \\
\text { особенным мышлением }\end{array}$ & - \\
\hline $\begin{array}{l}\text { Долгосрочность } \\
\text { предоставляемого } \\
\text { анализом прогноза }\end{array}$ & На несколько лет & + & $\begin{array}{l}\text { Прогноз на краткосроч- } \\
\text { ный период }\end{array}$ & - \\
\hline
\end{tabular}

\section{Baikal Research Journal}


У фундаментального анализа в рассматриваемой системе оценки, напротив, всего два плюса. Это многообразие инструментов анализа и долгосрочность предоставляемого в результате прогноза. Среди минусов находятся следующие признаки: сложность изучения и применения инструментов анализа: требуются знания бухгалтерской отчетности, методик расчета финансовых коэффициентов и их трендового анализа; значительный период времени для проведения анализа, требуемый значительный объем информации, знание специфики отрасли, проведение исследований в динамике за ряд лет. Все перечисленные моменты делают фундаментальный анализ громоздким, неудобным в использовании, а также недоступным для широкого круга инвесторов [12, с. 250].

Таким образом, рассмотренные в статье оба вида анализа фондового рынка представляют мощный инструмент оценки привлекательности ценных бумаг для инвесторов. Нет сомнений в том, что, используя оба вида анализа, инвестор примет верное и обоснованное решение. Государственное регулирование отечественного фондового рынка, в свою очередь, должно быть направлено на повышение уровня прозрачности рынка ценных бумаг.

Отметим также, что в 2014-2015 гг. государство стало предпринимать серьезные шаги по стимулированию физических лиц к инвестированию в отечественный фондовый рынок. Основным инструментом стимулирования авторы статьи считают введение индивидуальных инвестиционных счетов (ИИС). Согласно ст. 10.2-1, введенной Федеральным законом «О внесении изменений в отдельные законодательные акты Российской Федерации и признании утратившими силу отдельных положений законодательных актов Российской Федерации" от 29 июня 2015 г. № 210-ФЗ в Федеральный закон «О рынке ценных бумаг» от 22 апреля 1996 г. № 39-ФЗ, ИИС - счет внутреннего учета, который предназначен для обособленного учета денежных средств, ценных бумаг клиента - физического лица, обязательств по договорам, заключенным за счет указанного клиента, и который открывается и ведется в соответствии с настоящей статьей. Согласно ст. 219.1 «Инвестиционные налоговые вычеты» Налогового кодекса РФ (ред. от 29 дек. 2014 г. № 164) особенностью ИИС является предоставление физическому лицу налогового вычета в двух вариантах:

1. В размере $13 \%$ от суммы зачисленных на счет денежных средств.

2. В размере $13 \%$ от дохода по операциям, совершенным с использованием ИИС.

Согласно упомянутой статье совокупная сумма денежных средств, которые могут быть переданы в течение календарного года по такому договору, не может превышать 400 тыс. р. Это означает, что физическое лицо либо гарантированно может получить 52 тыс. р. в виде налогового вычета уже в следующем календарном году (при условии, что размер полученного из бюджета возврата налога не будет превышать суммы уплаченного лицом налога на доходы физических лиц), либо не уплачивать налог от дохода, полученного от выгодных операций продажи ценных бумаг. Отметим, что инвестор вправе сам выбирать тип налогового вычета, наиболее выгодный по результатам его торговых операций, совершенных с использованием ИИС.

По мнению авторов, при совершении торговых операций на ИИС было бы более логично использовать методы фундаментального анализа. Причиной этому являются следующие обстоятельства: договор ИИС исключает возможность вывода с торгового счета прибыли, полученной от операций с ценными бумагами. Получение денежных средств поэтому возможно только в случае досрочного расторжения договора на ведение ИИС, что повлечет за собой обязанность физического лица вернуть государству полученный им налоговый вычет. Следовательно, на ИИС можно использовать долгосрочные прогнозы, которые как раз предоставляет фундаментальный анализ.

\section{Baikal Research Journal}

электронный научный журнал Байкальского государственного университета 
Примечательно, что один из лауреатов Нобелевской премии в большей степени склонен к фундаментальному анализу (П. Хансен), другой - к техническому (Р. Шиллер), третий же считает, что оба бесполезны (Ю. Фама). Объединение противников в одну группу лауреатов представляет собой признание достижений тех, кто пытается ответить на один из важнейших вопросов современной мировой экономики: как случайные колебания цен в краткосрочном периоде определяют дефекты ценообразования в долгосрочном периоде и как это связано с психологией $[1$, c. 4].

\section{Список использованной литературы}

1. Сверчков Р. Эффективность финансовых рынков (Нобелевская премия по экономике 2013 года) / Р. Сверчков, К. Сонин // Вопросы экономики. - 2014. - № 1. - С. 4-21.

2. Звягинцева Н. А. Пути повышения инвестиционной активности в Российской Федерации с использованием механизмов рынка ценных бумаг: вопросы регулирования / Н. А. Звягинцева. - Иркутск : Изд-во БГУЭП, 2013. - 202 с.

3. Галактионова А. С. Нефтяное несчастье: российская экономика лишилась главного драйвера [Электронный ресурс] / А. С. Галактионова. - Режим доступа : http://www.rbc.ru/ business $/ 26 / 12 / 2014 / 549 \mathrm{c} 02 \mathrm{dd} 9 \mathrm{a} 794748 \mathrm{c} 322 \mathrm{a} 9 \mathrm{fa}$.

4. Шарп У. Инвестиции : пер. с англ. / У. Шарп, Г. Александер, Дж. Бэйли. - М. : Инकpa-M, 2007. - $1028 \mathrm{c.}$

5. Рынок ценных бумаг: учеб. для бакалавров / под общ. ред. Н. И. Берзона. - М. : Юрайт, 2011. - 531 с.

6. Ивасенко А. Г. Рынок ценных бумаг: инструменты и механизмы функционирования : учеб. пособие / А. Г. Ивасенко, Я. И. Никонова, В. А. Павленко. - 4-е изд., стер. - М. : КноРyc, 2015. $-272 \mathrm{c}$.

7. Фондовый рынок. Курс для начинающих : пер. с англ. / под ред. А. Ильина. - М. : Альпина Паблишер, 2002. - 277 с.

8. Теплова Т. В. Инвестиции: теория и практика : учебник / Т. В. Теплова. - 2-е изд., перераб. и доп. - М. : Юрайт, 2014. - 782 с.

9. Кан М. Н. Технический анализ. Просто и ясно (Трейдинг \& инвестиции) / Майкл Н. Кан. - СПб. : Питер, 2003. - 282 с.

10. Рынок ценных бумаг : учебник / под ред. Е. Ф. Жукова. - 3-е изд., перераб. и доп. М. : Юнити- Дана, 2009. - 567 с.

11. Инвестиционный анализ : учеб. пособие / под ред. И. С. Межова. - М. : КноРус, 2014. $-416 \mathrm{c}$.

12. Кузнецова Н. В. Механизм функционирования фондового рынка / Н. В. Кузнецова // Современное состояние и перспективы развития бухгалтерского учета, экономического анализа и аудита : материалы Междунар. науч.-практ. конф. Иркутск, 23 апр. 2016 г. / под ред. Е. М. Сорокиной. - Иркутск : Изд-во БГУ, 2016.

\section{References}

1. Sverchkov R., Sonin K. Financial market efficiency (Nobel Prize in Economics, 2013). Voprosy ekonomiki = Issues of Economics, 2014, no. 1, pp. 4-21. (In Russian).

2. Zvyagintseva N. A. Puti povysheniya investitsionnoi aktivnosti $v$ Rossiiskoi Federatsii s ispol'zovaniemmekhanizmov rynkat sennykh bumag: voprosyregulirovaniya [Ways of intensifying investment activity in the Russian Federation by using mechanisms of securities market: issues of regulation]. Irkutsk, Baikal State University of Economics and Law Publ., 2013. 202 p.

3. Galaktionova A. S. Neftyanoe neschast'e: rossiiskaya ekonomika lishilas' glavnogo draivera [Oil misfortune: Russian economy has been deprived of its major driver. Available at: http:// www.rbc.ru/business/26/12/2014/549c02dd9a794748c322a9fa. (In Russian).

4. Sharpe W. F., Alexander G. J. Alexander, Bailey J. V. Investments. Prentice Hall, 1995. 962 p. (Russ. ed.: Sharpe W. F., Alexander G. J. Alexander, BaileyJ. V. Investitsii. Moscow, Infra-M Publ., 2007. 1028 p.).

5. Berzon N. I. (ed.). Rynok tsennykh bumag [Securities Market]. Moscow, Yurait Publ., 2011. $531 \mathrm{p}$.

\section{Baikal Research Journal}


6. Ivasenko A. G., Nikonova Ya. I., Pavlenko V. A. Rynoktsennykhbumag: instrumenty $i$ mekhanizmyfunktsionirovaniya [Securities market: tools and mechanisms of functioning]. ${ }^{\text {th }}$ ed. Moscow, KnoRus Publ., 2015. 272 p.

7. An Introduction to Equity Markets. New York, John Wiley \& Sons, 1999. The Reuters Financial Training Series. (Russ. ed.: Il'in. A. (ed.). Fondovyi rynok. Kurs dly anachinayushchikh. Moscow, Al'pina Publisher, 2002. 277 p.).

8. Teplova T. V. Investitsii: teoriya i praktika [Investments: theory and practice]. $2^{\text {nd }}$ ed. Moscow, Moscow, Yurait Publ., 2014782 p.

9. Kan M, N. Technical Analysi. Plain and Simple. Prentice Hall, 2003. 282 p. (Russ. ed.: Kan M. N. Tekhnicheski i analiz. Prosto i yasno (Treiding \& investitsii). Saint Petersburg, Piter Publ., 2003. 282 p.).

10. Zhukov E. F. (ed.). Rynok tsennykh bumag [Securities market]. $3^{\text {rd }}$ ed. Moscow, YunitiDana Publ., 2009. 567 p.

11. Mezhov I. S. (ed.). Investitsionnyi analiz [Investment analysis]. Moscow, KnoRus Publ., 2014. $416 \mathrm{p}$.

12. Kuznetsova N. V. Mechanism of stock market functioning. In Sorokina E. M. (ed.) Sovremennoe sostoyanie i perspektivy razvitiya bukhgalterskogo ucheta, ekonomicheskogo analiza i audita. Materialy Международной nauchno-prakticheskoi konferentsii. Irkutsk, 23 aprelya 2016 g. [Today's State and Prospects of Developing Accounting, Economic Analysis and Auditing. Materials of International Science and Practice Conference, April 23, 2016, Irkutsk]. Irkutsk, Baikal State University Economics and Law Publ., 2016.

\section{Информация об авторах}

Кузнецова Наталья Викторовна - кандидат экономических наук, доцент, кафедра бухгалтерского учета, анализа, статистики и аудита, Байкальский государственный университет, 664003, г. Иркутск, ул. Ленина, 11, e-mail: n_smit@mail.ru.

Казанцев Леонид Викторович - старший преподаватель, кафедра информатики и кибернетики, Байкальский государственный университет, 664003, г. Иркутск, ул. Ленина, 11, e-mail: islimit@mail.ru.

\section{Authors}

Natalia V. Kuznetsova - PhD in Economics, Associate Professor, Chair of Accounting, Analysis, Statistics and Audit, Baikal State University, 11 Lenin St.,664003, Irkutsk, Russian Federation; e-mail:n_smit@mail.ru.

Leonid V. Kazantsev - Senior Instructor, Chair of Computer Science and Cybernetics, Baikal State University, 11 Lenin St., 664003, Irkutsk, Russian Federation; e-mail: islimit@mail.ru.

\section{Библиографическое описание статьи}

Кузнецова Н. В. Фундаментальный и технический анализ фондового рынка / Н. В. Кузнецова, Л. В. Казанцев / / Baikal Research Journal. — 2016. — T. 7, № 5. — DOI : 10.17150/2411$\underline{6262.2016 .7(5) .4}$.

\section{Reference to article}

Kuznetsova N. V., Kazantsev L. V. Fundamental and technical analysis of stock market. Baikal Research Journal, 2016, vol. 7, no. 5. DOI : 10.17150/2411-6262.2016.7(5).4. (In Russian).

\section{Baikal Research Journal}

